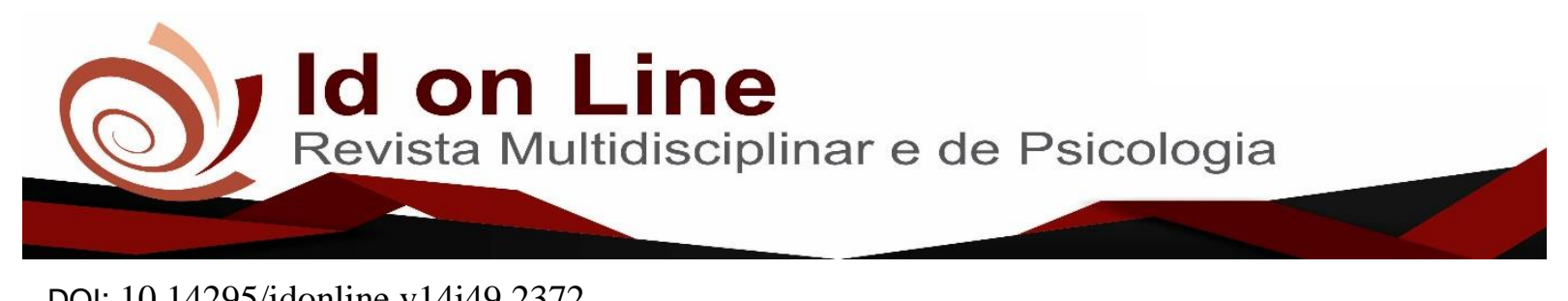

DOI: 10.14295/idonline.v14i49.2372

Artigo

\title{
A Educação no Campo e as Práticas Metodológicas
}

Giselle Pupim Jorge Back' ; Maria Ilmalucia Teixeira $^{2}$

Resumo: O presente artigo proporciona uma discussão acerca da produção e correção textual em atividades propiciadas por meio do desenvolvimento de um plano de ação aplicado no V Seminário do Campo realizado pelas escolas do campo do polo/sede de Alta Floresta no Estado de Mato Grosso, cujo objetivo foi garantir oportunidades para o diálogo, a troca de experiências e o aprofundamento da teoria, favorecendo a consolidação dos conhecimentos e integração do grupo para professores que atuam no Ensino Fundamental na educação do campo. A pesquisa foi realizada com dezessete professores que atuam nas turmas de primeiro ao nono ano. Como referencial teórico foi utilizado livros, revistas e internet com autores como Bakthin (1997), Geraldi (2004), Jolibert (1994), Machado (2007), Marcuschi (2001), Matencio (2001), Miller (1998), dentre outros. A pesquisa de caráter qualitativo utilizou como coleta de dados dois questionários respondidos em períodos diferentes com o mesmo público. Através da pesquisa percebeu-se que a formação ofertada apresentou resultado positivo contribuindo significativamente para a prática em sala de aula.

Palavra-chave: Formação; Prática docente; Reflexão.

\section{Rural Education and Methodological Practices}

\begin{abstract}
This article provides a discussion about the production and textual correction in activities provided through the development of an action plan applied at the Fifth Seminar of the Field held by the schools of the field / headquarters of Alta Floresta in the State of Mato Grosso, whose objective was to guarantee opportunities for dialogue, the exchange of experiences and the deepening of theory, favoring the consolidation of knowledge and integration of the group for teachers working in elementary education in rural education. The research was carried out with seventeen teachers who work in classes from the first to the ninth year. As a theoretical framework, books, magazines and the internet were used with authors such as Bakthin (1997), Geraldi (2004), Jolibert (1994), Machado (2007), Marcuschi (2001), Matencio (2001), Miller (1998), among others. The qualitative research used two questionnaires answered in different periods with the same public as data collection. Through the research it was realized that the training offered presented a positive result, contributing significantly to the practice in the classroom.
\end{abstract}

Keyword: Formation; Teaching practice; Reflection.

\footnotetext{
${ }^{1}$ Graduação em Pedagogia pela União das Faculdades de Alta Floresta. Pós graduação em Educação Interdisciplinar de $1^{\circ}$ a $4^{\circ}$ série do Ensino Fundamental. Mestranda do Instituto IESA. Docente formadora do Centro de Formação e Atualização de Profissionais da Educação Básica/CEFAPRO-MT. giselle.pupim@gmail.com;

${ }^{2}$ Graduação em Ciências Biológicas pela Universidade do Estado de Mato Grosso. Mestrado em Agronomia pela Universidade Federal de Viçosa. Bacharela em Serviço Social pelo Centro Universitário da Grande Dourados. Professora efetiva da rede estadual de Mato Grosso. ilmalucia1968@gmail.com.
} 


\section{Introdução}

O V Seminário do Campo, realizado pelas escolas do campo do polo/sede de Alta Floresta no Estado de Mato Grosso buscou-se promover uma reflexão acerca da produção textual como possibilidade de aprendizagem na educação no campo. O processo se concretizou através de uma oficina buscando relacionar teorias e práticas no ensino dos Gêneros Textuais objetivando reflexão, discussão, análise de experiências e práticas pedagógicas que permitam a consolidação dos conhecimentos dos alunos.

Nessa oficina, será fomentado estudos sobre leitura, escrita e produção textual pa onde o professor possa se permitir analisar a relação entre a prática da produção textual e o processo de construção de conhecimento dos estudantes, além de refletir a respeito das práticas educativas realizadas.

Esses questionamentos permeiam o ambiente escolar desde muitos anos. Porém a pesquisa visa esclarecimentos e contribuições haja visto que é praticamente impossível solucionar completamente tais desafios, uma vez que o público atendido sempre estará em constante evolução apresentando a cada nova escrita um novo desafio.

O propósito consiste em permitir um redirecionamento da prática e proporcionar aos professores das Escolas Estaduais do Campo um esquadrinhamento quanto ao conhecimento sobre as atividades de leitura e escrita, procurando amenizar as dificuldades cotidianas que envolvam o professor em sala de aula. Essa análise minunciosa deu-se través de propostas metodologias que instrumentalizem a prática pedagógica no recinto escolar, visando melhoria nas ações educativas, adequando-as às reais necessidades nessa comunidade escolar, auxiliando os alunos no que diz respeito ao processo da construção do conhecimento para aumento da proficiência e correção do fluxo escolar. Portanto, a proposta se justifica, na medida em que se faz necessário compreender o processo de ensino e de aprendizagem dos alunos, uma vez que estudando a correção há a possibilidade de se contribuir para o redimensionamento das práticas de ensino.

\section{Os Desafios da Educação no Campo}

Com o advento das transformações da sociedade os moradores do campo procuraram melhores condições de vida na cidade. Dessa forma, inevitavelmente a escola teve que abranger 
esse espaço com uma educação voltada para o campo e necessariamente no campo, buscando resgatar a identidade desses camponeses que ainda habitam no campo.

Para atender as demandas existentes no campo as escolas precisam organizar um currículo que objetive contemplar essas necessidades voltadas para o desenvolvimento sustentável. Como metodologia algumas escolas aderiram a Pedagogia da Alternância, visando uma redistribuição dos currículos em conformidade com as demandas locais. Esse tipo de método visa a criação de um elo entre a vida no campo e a realidade do aluno.

Essa metodologia surgiu na França em 1935, com a intenção de se diminuir o tempo de deslocamento até a cidade ou mesmo que tivessem que se deslocar definitivamente para centros urbanos. Em 1969, com a missão dos jesuítas os filhos dos camponeses apresentaram dificuldades com o transporte escolar, assim a metodologia ganhou espaço também no Brasil. Assim, a luta pela educação do campo nasce junto com as lutas pelas terras.

A educação do campo não consiste somente em uma escola localizada no campo, mas com projetos e programas voltados para os camponeses conforme destaca Henrique (2007)

\footnotetext{
Dentre elas o reconhecimento e a valorização da diversidade dos povos do campo, a for- mação diferenciada dos professores, a possibilidade de diferentes formas de organização da escola, a adequação dos conteúdos às peculiaridades locais, o uso de práticas pedagógicas contextualizadas, a gestão democrática, a consideração os tempos pedagógicos diferenciados, a promoção, através da escola, do desenvolvimento sustentável e do acesso aos bens econômicos, sociais e culturais. (HENRIQUES et al., 2007, p. 17).
}

Henrique (2007) destaca também a importancia de que a educação no campo seja feita por pessoas do campo e não uma educação da cidade instituída somente em outro lugar. Que essa educação do campo conte com maneiras diferentes de se observar a mesma esfera educacional, partindo de cada realidade

\section{Seminário do Campo: Contextualizando um Sonho}

O V seminário do campo surgiu em 2014, a partir da iniciativa do Centro de Formação e Atualização dos Profissionais da Educação de Mato Grosso/CEFAPRO do Pólo de Alta Floresta em parceria com a Secretaria Municipal de Educação e com o apoio da Assessoria Pedagógica de Alta Floresta e das escolas estaduais e municipais do campo. Inicialmente foram realizadas reuniões nas dependências do CEFAPRO visando discutirem sobre a possibilidade da organização de um evento com o intuito de debater questões ligadas à Educação do Campo. 
Em um segundo momento, as reuniões contaram com a participação dos diretores das escolas estaduais e municipais do campo do município de Alta Floresta.

Nos dias 25 e 26 de setembro do mesmo ano, houve a realização do I SEMINÁRIO DA EDUCAÇÃO DO CAMPO na Escola Estadual Ouro Verde. Nesse momento os participantes eram poucos e as próprias escolas faziam arrecadações para que acontecessem os dois dias de evento. As escolas serviam de alojamento para os participantes e as refeições eram servidas no local do evento.

O evento objetivou relacionar e debater as Políticas Públicas da Educação do Campo e os Planos estadual e Municipal de Educação, além de permitir a discussão de práticas pedagógicas específicas da educação do campo. Nesse viés, participaram cerca de 135 pessoas das escolas Ouro Verde, Boa Esperança, Guimarães Rosa, Rodrigues Alves, Aluizio de Azevedo, Paulo Cézar Leinig, Castelo Branco de Alta Floresta e as escolas de Colorado do Norte Ivone Borkowski e São Manoel. Dentre as atividades realizadas destacou-se palestras, vivências pedagógicas e oficinas pedagógicas ministradas pelos formadores do CEFAPRO e por professores das escolas do campo. O evento contou com a participação de representantes da SEDUC, Secretaria Municipal de Educação e CEFAPRO que estavam coordenando o evento.

O II Seminário do Campo aconteceu nos dias 27 e 28 de agosto de 2015 na Escola Estadual Mundo Novo, contando com a participação da Secretaria Municipal de Meio Ambiente e Agricultura onde discutiram sobre as perspectivas curriculares para a Educação no Campo. O evento foi marcado por palestras, apresentações, mesas redondas e debates buscando ampliar as discussões da Educação no Campo. Com uma conversa sobre as "Instituições Formativas: Contexto Técnico, Pedagógico e Formativo" a secretária de Meio Ambiente e Agricultura, Aparecida Sicuto, destaca a importância desses eventos para contribuir em auxiliar e capacitar o produtor, para melhorar os nossos produtos oriundos da agricultura familiar.

O III Seminário de Educação do Campo do Polo de Alta Floresta, com o tema “Educação no Campo e a Vida camponesa: A invenção de Novas Formas de Sociabilidade", aconteceu nos dias nos dias 22 e 23 de setembro de 2015, na Gleba São Pedro, comunidade Sombra da Manhã em Paranaíta-MT. O Prof. Luiz Carlos dos Santos participou do debate sobre o "Ensino: Qualificação, Produção e Qualidade de vida" destacando a importância do aproveitamento dos conhecimentos trazidos do cotidiano do campo para o processo ensinoaprendizagem. 
Nos dias 24 e 25 de agosto de 2017, o IV Seminário da Educação do Campo aconteceu na Escola Estadual Ivone Borkowski de Lima, localizada no Distrito de Colorado do Norte, em Nova Canaã do Norte - contando com, aproximadamente, 450 participantes de unidades escolares das redes estadual e municipais dos municípios de Alta Floresta, Carlinda, Nova Canaã do Norte, Nova Monte Verde e Paranaíta. Partindo do tema "Perspectivas e desafios da construção do Projeto Político Pedagógico na Educação do Campo", buscou discutir as Políticas Públicas e a Educação do Campo através de debates que pudessem contribuir para a melhoria educação, além de socializar vivências metodológicas das escolas do campo.

O V Seminário do Campo aconteceu nos dias 23 e 24 de agosto na escola Frei Caneca no município de Carlinda, com aproximadamente 600 participantes. $\mathrm{O}$ evento contou com a participação da equipe do CEFAPRO, a prefeita de Carlinda, o presidente da Câmara, a Assessora Pedagógica, a Secretária Municipal de Educação, a diretora Regional do Nortão II do Sintep. O seminário contou também com a participação dos municípios de Alta Floresta, Nova Canaã do Norte, Nova Monte Verde, Paranaíta e Carlinda. Houve a participação do professor mestre do IFPR João Luis, destacando "O currículo na escola do campo com vista na BNCC”, bem como oficinas voltadas a educação no campo.

\section{A Produção Textual como expressão do pensamento, da comunicação e da interação}

Mesmo a produção textual fazendo parte da rotina das salas de aula desde o primeiro ano do Ensino Fundamental, percebe-se que ao encerrar os estudos muitos sentem-se despreparados para executá-la. E além dessa dificuldade os estudantes ainda possuem desafios na própria língua padrão, fator que impede a sintetização de suas ideias.

A linguagem constutui, como afirma Koch (2012), três concepções: como expressão do pensamento, comunicação e interação. Assim, a linguagem torna-se um acesso constante entre o locutor e o interlocutor, tanto na escrita quanto na fala. Dessa forma o término dos doze anos entre o Ensino Fundamental e o Médio permitiriam aos alunos comunicar-se tanto pela fala quanto pela escrita e serem entendidos.

Ao proporcionar uma produção textual o professor permite que o aluno expresse seu pensamento, comunique-se e enteraja com a sociedade. Sabe-se que diversas atividades gramaticais e ortográficas podem propiciar essa interação, no entanto nos ateremos a produção enquanto ferramenta social de comunicação e prossibilidade de aprendizagem. 
Dessa forma, a sala de aula deixa de ser apenas um lugar de transmissão/recepção de um conhecimento arbitrário e passa a ser um "evento social no qual, através de procedimentos interacionais, professor e alunos tentam construir significado e conhecimento" (MOITA LOPES, 1996, p. 349).

Essa proposta interacionaista de produção textual, onde o autor reconhece a interação de uma texto com a linguagem social, pode ser constantemente trabalhada em sala de aula. Dessa forma as produções não serão mais um aglomerado de escritas referente a suas férias ou as datas comemorativas somente. Jolibert (1994) destaca que

\footnotetext{
É preciso que, para cada criança, o escrever não seja sinônimo de trabalho enfadonho, fracasso, mas que evoque, em vez disso, projetos realizados graças à escrita: é preciso escrever, seja fazer um cartaz para anunciar uma exposição, fazer um relatório de visita, escrever poemas etc., em lugar de fazer exercícios de gramática, completar frases, fazer ditados, etc. (JOLIBERT, 1994, p. 16)
}

A repetição de metodologias para as produções textuais fazem com os alunos não se interessem por produzir. Geraldi (2006) alerta que o aluno percebe que produzirá para o professor, que será seu único leitor. Assim, o aluno utiliza somente a concepção de pensamento e comunicação. Quando esses textos são trocados entre os alunos, socializados na escola ou mesmo fora dela. eleva-os até a concepção de interação, atingindo de fato as três concepções proposta por Koch (2012).

Ele pode produzir esses textos partindo do pressuposto que a verdadeira substância da língua é formada por um fenômeno social, com a finalidade de comunicacão, sendo assim necessita muito mais do que simples letras, e sim de uma interação entre sujeitos (BAKHTIN/VOLOCHİNOV, 2006, p. 123). O estudante precisa compreender que através dessas relações, tanto escrita quanto falada, gera conhecimento e experiência.

Assim, podemos afirmar que um texto nada mais é que as intencões do escritor sobre uma determinada ideia partindo do seu contexto sócio-cultural. Ou como o próprio autor referese, cada discurso apresenta marcas características da esfera social que o escritor está inserido.

Segundo Miller (1998, p.10), “quando se escreve, está em jogo produzir um texto que faça sentido para o leitor e, da mesma forma, quando o leitor coloca-se diante de um texto escrito, está em jogo buscar o sentido nele expresso."

Assim, ao produzir um texto o aluno deve observar pontos como a coesão, coerência, argumentação, organização de ideias, dentre outros. Deste modo, cada texto tem sua função e 
todas essas possíveis manifestações escritas devem ser trabalhadas em sala de aula. Sobre isso, os PCNs (BRASIL, 1997, p. 24) esclarecem:

Uma rica interação dialogal na sala de aula, dos alunos entre si e entre o professor e os alunos, é uma excelente estratégia de construção do conhecimento, pois permite a troca de informações, o confronto de opiniões, a negociação dos sentidos, a avaliação dos processos pedagógicos em que estão envolvidos. (Brasil, 1997, p. 24)

\section{Função Discursiva e a perspectiva intencional de um texto}

Os textos produzidos em sala de aula além de exercitar a escrita, também prepara para o uso futuro dessa escrita. Para que esse objetivo seja atingido precisa-se ir além de conceitos gramaticais e ortográficos, proporcionando uma reflexão acerca da função discursiva e a perspectiva intencional desse texto.

No entanto nem todas as atividades escritas propostas em sala apresentavam finalidade e função social. Partindo dessa realidade, os Parâmetros Curriculares Nacionais em 1998 reformulam a visão de produção textual.

O domínio da língua, oral e escrita, é fundamental para a participação social efetiva, pois é por meio dela que o homem se comunica, tem acesso à informação, expressa e defende pontos de vista, partilha ou constrói visões de mundo, produz conhecimento. Por isso, ao ensiná-la, a escola tem a responsabilidade de garantir a todos os seus alunos o acesso aos saberes linguísticos, necessários para o exercício da cidadania, direito inalienável de todos. (Parâmetros Curriculares Nacionais, 1997, p. 15)

Nessa nova proposta todas as produções precisam interagir socialmente além de ter um caráter social. Assim, o estudante passou a ter contato com gêneros textuais antes não vistos, como e-mail, SMS, bilhetes, listas de telefones e outros gêneros que levassem o aluno a compreender que fora dos muros da escola há uma linguagem que precisa ser compreendida.

Cabe, assim, ao professor viabilizar momentos de interação com esses novos gêneros textuais socialmente utilizáveis. No entanto, Geraldi (2006) afirma ser impossível o aluno compreender a escrita como preparação do seu futuro se as atividades não partirem de sua realidade.

Quando o aluno compreende que escreve-se para alguém e sempre com um objetivo, seja de comunicação ou interação, a contextualização acontece. Antunes (2005, p. 32) nos 
recorda que o ato da escrita é uma atividade intencional e que cada texto tem um objetivo determinado.

Porém para que o leitor possa compreender o objetivo do texto faz-se necessário que ele compreenda o que está escrito. Para isso, o aluno precisa escrever o texto corretamente sendo necessário conhecer as regras gramaticais e ortográficas haja vista, que somente com o conhecimento de sua língua materna é possível transmitir ideias ao leitor.

Porém isso não quer dizer que somente os alunos que possuem todas as regras da língua portuguesa são capazes de redigir textos, uma vez que a escrita espontânea também permite comunicações, sendo um princípio de aprendizagem. Conforme afirma Soares (1999, p. 51), os erros cometidos pelas crianças fazem parte da construção da escrita, sendo assim construtivos. Dessa forma um aluno do primeiro ano pode produzir textos sociais mesmo sem ter se apropriado integralmente da língua portuguesa.

Vale destacar que ao redigir um texto o aluno precisa ir além de seus conhecimentos linguísticos, é preciso saber sobre o assunto que irá escrever. Para que haja conhecimento sobre o assunto é necessário que sejam feitas leituras e conhecer o contexto social no qual se está inserido.

Nota-se, assim, que a produção um texto é muito mais que "formigas pretas" no papel, é preciso ter conhecimentos para passar para o leitor e compartilhar ideias. Tornando uma prática social e não somente individualizada.

\section{Gêneros Textuais e sua importância em Sala de Aula}

\section{Tipologia X Gênero}

Todo texto produzido, seja oral ou escrito, pode ser classificado segundo sua estrutura ou função social. Quando nos remetemos a estrutura específica, seja partido das regras gramaticais ou ortográficas ou sua coesão e coerência, estamos classificando as tipologias textuais.

Assim, ao notar que um texto possui em sua estrutura características que descrevem algo destaca-se como texto descritivo, ou mesmo que seus verbos indicam ordens a serem seguidas classificando-o como injuntivo. Dessa forma, um determinado texto não precisa ter predominantemente uma tipologia e sim mais de uma dentro de um mesmo texto. Deste modo, 
podem-se classificar os textos, quanto às tipologias textuais, em: narração, descrição, dissertação, exposição, injunção e conversacional.

O texto que predomina a narração de ações e personagens classifica-se como narrativo, como exemplo temos os contos de fadas como "Cinderela". Na descrição, o escritor precisa formular no pensamento do leitor uma imagem ou situação definida do que se quer mostrar, como exemplo temos a descrição dos locais de viagem nos guias turísticos.

Quando proporciona-se um debate expondo pontos de vistas sobre determinado assunto, definimos esse texto como dissertativo ou dissertação. As dissertações são comuns nas conclusões de curso. Já a exposição esclarece-sa sobre um assunto sem emitir opiniões como na dissertação.

Os textos injuntivos exprimem orientação sobre o uso de determinado aparelho, ditando regras ou instruindo, como os manuais de instrução ou receitas culinárias. Finalmente o conversacional ou dialogal consiste na presença de dois interlocutores em uma conversação, como exemplo temos as entrevistas.

Referimo-nos aos gêneros textuais quando obsevarmos a finalidade ou função social de detreminado texto, seus interlocutores, ou mesmo o local que essa comunicação acontece,. Nessa segunda observação destacamos as receitas, cuja finalidade é ensinar a fazer um bolo ou mesmo os e-mais que permitem uma comunicação virtual rápida.

Os gêneros textuais, diferentemente das tipologia não são quantificadas, os gêneros textuais são infinitos, uma vez que a sociedade também apresenta modificações a todo instante e os gêneros textuais estão intimamente ligados a ela. Cada gênero textual apresenta seu próprio estilo e configura-se assim por manifestações socialmente reconhecidas. Cita-se aqui as cartas, histórias em quadrinhos, e-mail, contos de fadas entre tantos.

Marcuschi (2002) afirma que:

Fruto de trabalho coletivo, os gêneros contribuem para ordenar e estabilizar as atividades comunicativas do dia-a-dia. São entidades sócio-discursivas e formas de ação social incontornáveis em qualquer situação comunicativa. Os gêneros textuais surgem, situam-se e integram-se funcionalmente nas culturas em que se desenvolvem. (Marcuschi, 2002, p. 20)

Os gêneros textuais trabalhados na escola vão muito além das meras características formais. Dessa forma ao ensinar para o aluno que a receita culinária possibilita aprender a fazer algo, ou mesmo que em uma entrevista duas pessoas dialiga não significa que ele produzirá sozinho e compreenderá o gênero abordado. $\mathrm{O}$ estudante precisa conhecer a intencionalidade 
do texto mas também precisa vivenciar situações que permitam a sua produção. "O que importa é fazer a garotada transitar entre as diferentes estruturas e funções dos textos como leitores e escritores", explica a linguista Beth Marcuschi, da Universidade Federal de Pernambuco (UFPE).

Dessa forma só é possível compreender a função de um texto quando essa é executável, ou seja, para entender para que serve uma notícia o aluno precisa ler uma e até mesmo produzir uma notícia para alguém ler. Somente assim, o aluno perceberá a importância da norma culta e das regras da língua portuguesa.

De acordo com Marcuschi (2008, p. 209), em sala de aula "consideram-se apenas os gêneros com realização linguística mais formal e não os mais praticados nas atividades cotidianas". Relata ainda:

Os PCNs não negam que haja mais gêneros, mas estes não são lembrados. Porque não trabalhar telefonemas, conversações espontâneas, consultas, discussões etc., para a fala? Porque não analisar formulários, cartas, bilhetes, documentos, receitas, bulas, anúncios, [...] diários, ata de condomínio e assim por diante, para a escrita? (Marcuschi 2008, p. 209)

\section{Correção: permissão para as Novas Estratégias}

Destacou-se até o presente momento a importância dos trabalhis desenvolvidos com a produção textual, todavida vale destacar a valorização da correção desses textos enaunto diagnóstico para novas estratégias metodológicas que nortearão os demais trabalhos relizados, bem como visualizar os avanços dos alunos.

Mediante a esses processos de produção textual o professor pode realizar interferências que permita aos alunos visualizar e compreender seus próprios erros, permitindo assim, reflexões e construções.

Essas reflexões torna-se imprescindível possibilitando ao aluno observar que aundo se escreve é fundamental que (GERALDI, 1993):

\footnotetext{
$\checkmark \quad$ se tenha o que dizer;

$\checkmark \quad$ se tenha uma razão para dizer o que se tem a dizer;

$\checkmark \quad$ se tenha para quem dizer o que se tem a dizer;

$\checkmark \quad$ o locutor se constitua como tal, enquanto sujeito que diz o que diz;

$\checkmark \quad$ se escolham as estratégias para realizar (a), (b), (c), (d). (GERALDI, 1993, p.137)
} 
Em alguns estudos, Ruiz (2001) pesquisa como essas produções textuais são corrigidas na escola partindo de um grupo pequeno de professores da educação básica, Assim, Ruiz cataloga quatro tipos de correções que são assim descritas, com base em Serafini (1989):
a) correção resolutiva: solução dos problemas detectados nos textos;
b) correção indicativa: marcas deixadas no texto para apontar os problemas encontrados;
c) correção classificatória: marcas de metalinguagem codificada para apontar a natureza dos problemas encontrados nos textos;
d) correção textual-interativa: bilhetes deixados pelo professor, os quais visam estabelecer interlocução com o aluno sobre problemas e acertos no texto.

A correção tem como objetivo chamar a atenção do aluno para determinado problema (RUIZ, 2001). Assim, a ação de correção feita pelo educador torna-se fundamental para o desenvolvimento integral do aluno. Isso porque é por ela que o aluno percebe o que é ou não pertinente para seu texto, e também, pela correção, o professor expõe, para o aluno, quais os problemas existentes em seu texto. $\mathrm{O}$ que, por via de regra, deveria gerar uma reflexão sobre a escrita.

Ruiz (2001, p. 215), assinala que "a correção pela mera correção não tem fundamento". Detalha ainda, que "os sinais de correção empregados pelo professor são as marcas que ele deixa para o aluno (e para nós, analistas), do seu projeto de dizer”. Esse processo de análise e correção do professor no texto do aluno, pode oferecer uma boa contribuição para a reflexão da linguagem escrita. A análise da ação de correção proposta neste trabalho volta-se para as atividades de retextualização e separação de item gerado pelas dificuldades dos alunos.

Marcuschi (2001, p. 70), em trabalho sobre retextualização, afirma que "para poder transformar um texto é necessário compreendê-lo ou pelo menos ter uma certa compreensão dele”. Para que isso aconteça, é necessário se ter um texto como base para uma posterior elaboração do conceito do gênero. Ainda para o autor citado anteriormente, para retextualizar, é preciso compreender o texto "principal".

Neste aspecto as atividades sugeridas devem conter gêneros do domínio do aluno, para que ele desenvolva os conceitos científicos para a assimilação do gênero. Ao se iniciar esse tipo de aprendizagem faz-se necessário saber o que o aluno apresenta de conhecimento sobre o assunto. Para Moscovici (2003, p. 52), “existe um comportamento adequado para cada circunstância, uma fórmula linguística para cada confrontação e [...] a informação apropriada para um contexto determinado". 


\section{Análise de Dados}

As produções e correções textuais são temas discutidos em todos os encontros de professores. Através de uma oficina realizada no V Seminário do Campo na escola pública da cidade de Alta floresta no Estado do Mato Grosso visou-se proporcionar uma discussão acerca da produção e correção textual em atividades para garantir oportunidades para o diálogo, a troca de experiências e o aprofundamento da teoria, favorecendo a consolidação dos conhecimentos e integração do grupo para professores que atuam no Ensino Fundamental ( $1^{\circ}$ ao $5^{\circ}$ ano) na educação do campo. A oficina contou com quinze participantes, sendo quatorze que atuam do primeiro ao quinto ano e uma professora de língua portuguesa dos anos finais.

Após a explanação dos aportes teóricos que embasaram o desenvolvimento do plano de ação foram realizadas atividades com todos os professores. Os participantes realizaram altercações pertinentes sobre o tema. Foram repassadas algumas atividades que poderiam ser realizadas através de histórias em quadrinhos ou mesmo vídeos de curta-metragem. As professoras elencaram quais conteúdos e metodologias poderiam ser trabalhados em suas salas multifaseadas, permitindo assim um olhar mais profundo sobre as adequações curriculares.

Dentre esses conteúdos e metodologias destacaram a realização de produção coletiva para que os alunos tenham noções sobre as atividades posteriores. Ao se trabalhar com histórias em quadrinhos destacaram o que poderia ser realizado partindo da mesma história e contemplar os anos que a escola trabalha, como a lista de personagens no primeiro ano. Para o segundo ano, merece destaque as frases, pois destacam as características dos personagens que aparecem na história. No terceiro ano destacamos a escrita de frases para cada quadrinho, o qual pode ser introduzindo a noção de paragrafação. No quarto e quinto ano destacaram o trabalho com as falas dos balões e a pontuação, além de expor a estrutura dos textos em prosa e a linguagem mista usada nos quadrinhos.

A professora dos anos finais elencou que trabalha com a história em quadrinhos através de transposição de falas nos balões e correção dessas falas, no caso específico do Cebolinha e Chico Bento, da Turma da Mônica. Além de apontar que procura trabalhar com as personagens da Turma da Mônica Teens, por se tratar de uma linguagem mais adequada a idade de seus alunos. 
O mesmo trabalho foi realizado com textos preditivos, no caso específico da previsão do tempo. No entanto a participação dos professores não foi tão concentrada, devido ao gênero não ser muito difundido nas salas de aula. Mesmo assim, elencaram pontos importantes como condições climáticas, representação da vegetação por meio de desenhos ou aplicativos e organização pelos alunos de vídeos de curta-metragem.

Em sequência o trabalho foi direcionado para a correção textual. Partindo das correções destacadas por Ruiz (2001) e Serafini (1989), foram apresentados textos que embasassem a parte teórica. Para a correção resolutiva que parte de alguns problemas detectados no texto, foi apresentado três modelos de textos corrigidos pelos professores que adotam essa prática. A professora dos anos finais destacou que esse tipo de correção é a mais usual por ela e por outros professores na escola onde leciona.

A segunda correção indicativa que configura como as marcas deixadas no texto para apontar os problemas encontrados, foi a única utilizada pelas quatorze professoras dos anos iniciais, até uma professora que atende a educação infantil relatou que faz uso dessa correção nas escritas espontâneas das crianças. Foi exposto cinco textos com esse tipo de correção nos quais as professores se identificaram.

A próxima correção classificatória que consiste em marcas de metalinguagem codificada para apontar a natureza dos problemas encontrados nos textos foi destacada pelo seu desuso. As professoras elencaram que dessa forma precisam voltar e corrigir o texto dos alunos novamente e que muitas vezes não conseguem fazer o trabalho de correção uma única vez. Mesmo com os cinco exemplos apontados as professoras desconheciam esse tipo de correção.

A correção textual-interativa: bilhetes deixados pelo professor, os quais visam estabelecer interlocução com o aluno sobre problemas e acertos no texto, já foi utilizada pelas professoras, mas na forma de incentivos e nem sempre como correção pontual. Foram apresentados seis tipos de bilhetes deixados pelos professores nos textos, no entanto nenhum já utilizado pelas professoras.

Inicialmente as professoras receberam um texto fatiado com a fábula do "leão e o ratinho", em conjunto organizaram o texto colando-o em uma cartolina. Alguns pontos foram elencados pelas professoras como a oportunidade de trabalhar com essa atividade desde o primeiro ano, através de texto de domínio dos alunos, e também com os alunos maiores, com texto que não conheçam. 
A segunda atividade a ser desenvolvida foi a montagem do galo com o recorte do carimbo das mãos. Após desenharem suas mãos em papéis coloridos as professores fizeram o recorte e montaram um galo com esses carimbos. Deram nome ao galo e salientaram que poderiam trabalhar com fichas catalográficas ou mesmo textos em prosa a partir dessa atividade.

No final da formação foi entregue uma ficha avaliativa para cada professor. Essa primeira ficha avaliativa realizada no mesmo dia da oficina constou com dez participantes, os demais professores não responderam ou não entregaram.

O primeiro aspecto a ser observado foi quanto a exposição teórica sobre a produção e correção textual. Todos os dez participantes caracterizaram a formação como ótima, dentre os quesitos ótima, boa, regular e ruim. Alguns professores elencaram não terem nenhum tipo de contato com os autores citados na oficina. Elencaram utilizar muitas metodologias expostas mas não sabiam que eram referenciadas por esses autores.

No segundo ponto avaliado sobre os planejamentos com as produções e correções textuais também obteve destaque entre os participantes que elencaram a valorização das sequências didáticas e a diferenciação das atividades. Ressaltaram que muitos gêneros textuais que são comumente trabalhados pela mídia podem ser adaptados para a educação no campo, como foi abordado as histórias em quadrinhos com temas da zona rural.

Quanto a distribuição do tempo e os recursos utilizados na formação, dos dez participantes somente um destacou que a distribuição do tempo não foi favorável, visto que a oficina que deveria iniciar às treze horas e trinta minutos iniciou às quatorze horas e quinze minutos. Sendo assim, algumas atividades não conseguiram ser concluídas.

Ao elencar acerca da contribuição para a prática, todos os participantes destacaram a formação como ótima, sendo que uma professora ainda apontou "parabéns a professora pelo trabalho e pela contribuição a prática na sala" (professora 01). Como sugestão frisaram a possibilidade de trazer a formaçao para o municipio de Carlinda como formação de professores.

No final do V Seminário foi entregue uma outra ficha para avaliar todo o trabalho desenvolvido nos dois dias na escola Frei Caneca. Essa ficha foi entregue para todos os profissionais e separada por oficinas, no Centro de Formação e Atualização dos Profussionais de Educação Básica de Alta Floresta/Mato Grosso. Nessa segunda ficha seis professores avaliaram a oficina como ótima e uma como excelente. Como sugestão salientaram que "os materiais e a forma da prática podia ser repensada" (professor 02). 
Uma dos participantes na avaliação final também acentuou que "só a questão do tempo, foi muito curto para desenvolver as atidades práticas" (professor 03), retomando a situação já dia anteriormente.

\section{Considerações Finais}

Todas a atividades realizadas na oficina do V Seminário do Campo proporcionaram reflexões acerca da possibilidade de se realizar a produção textual e a correção de todas as propostas realizadas pelo professor em sala de aula, através de intervenções. Para que isso seja possível o educador precisa desenvolver metodologias que possibilitem um envolviemnto e avanço no processo de leitura e escrita. Também, vale destacar que os professores da educação no campo precisam partir de situações as quais os alunos tenham conhecimento, fazendo sempre a relação com a realidade. Nessa oficina, além de vivenciar situações diversas de produção procurou-se demonstar maneiras de corrigir as produções dos alunos sempre permitindo um retorno ao final de cada produção.

No decorrer da oficina pode-se perceber o desafio enfrentado mediante as atividades de escrita e correção dos alunos. Mesmo com metodologias diversificads os professores alegaram que não conseguem realizar as correções em todos os textos e que muitas vezes levam todo o trabalho para casa. Também destacaram que muitos textos são corrigidos mas nunca devolvidos para os alunos para revisões posteriores.

Ao iniciar o trabalho com as tipologias e gêneros observou-se o desafio dos professores quanto aos conceitos específicos da diferenciação entre tipologia e gêneros. Muitos conseguiam dar exemplos práticos, no entanto sem conceituá-los. Um dos professores afirmou ter dificuldade em sala de aula também. Dessa forma as reflexões foram importantissimas para dar continuidade aos trabalhos.

Notou-se também, a falta de auxílio por parte da coordenação nas produções, afirmando ser um trabalho totalmente solitário dos professores. Afirmaram que não há na rotina da coordenação um momento para auxiliar ou amenizar esses anseios. Contudo, deparou-se com profissionais que, mesmos solitários, realizam estratégias metodológicas que permitem aos seus alunos progredirem, conseguindo fazer de seus alunos sujeitos hábeis na compreensão e na construção de significados por meio das atividades de leitura e escrita. 
A utilização da produção textual para os professores que participaram da oficina é entendida mais como uma forma de avaliação do que uma ferramenta de aprendizagem. Além do livro didático ser o único recurso de leitura desses alunos. Nas atividades propostas pelo formador os professores elencaram que não pensaram ser possível ensinar a escrever partindo de bulas de remédios ou com carimbo das palmas das mãos.

Percebeu-se que muitos dos professores partem das produções usando a realidade dos alunos, destacando muitas atividades a partir da horta que possuem na escola ou dos animais que os pais criam nas chácaras e sítios. Esse fator possibilita o estudante compreender a função social dos textos trabalhados pelo professor.

Os professores destacaram a necessidade de mais trabalhos desse viés serem realizados nas escola do campo. Um dos professores destacou que o V Seminário do Campo é uma iniciativa do Centro de Formação e Atualização dos Profissionais da Educação de Mato Grosso (CEFAPRO) de Alta Floretasta em parceria com a Secretaria Municipal de Alta Floresta e os diretores das escolas do campo e que o governo, mesmo contribuindo para manter essas escolas funcionando, não auxilia com recursos para esses tipos de eventos, não incentivando suas realizações.

\section{Referências}

BAKHTIN, M. Estética de criação verbal. São Paulo: Martins Fontes, 1997.

BRASIL. Ministério da Educação e do Desporto. Parâmetros Curriculares Nacionais -Língua Portuguesa-3 ${ }^{\circ}$ e $4^{\circ}$ ciclos.Brasília:MEC,1998.

GERALDI, João Wanderlei. Da redação à produção de textos. In: CHIAPPINI, L. (Coord.). Aprender e ensinar com textos de alunos. 6. ed. São Paulo: Cortez, 2004. v. 1.

GERALDI, João Wanderley. O texto na sala de aula. Edição 4. São Paulo: Ática, 2006. p. 136.

JOLIBERT, J. (Coord.) Formando crianças produtoras de textos. Porto Alegre: Artmed, 1994, v. II.

KOCH, Ingedore Grunfeld Villaça; ELIAS, Vanda Maria. Ler e escrever: estratégias de produção textual. 2. ed. São Paulo: Contexto, 2010.

KOCH, Ingedore Grunfeld Villaça; ELIAS, Vanda Maria. 1.Leitura, texto e sentido; 2.Leitura, Sistemas de conhecimento e Processamento Textual; 3. Texto e Contexto; 4. Texto e 
Intertextualidade; 5. Gêneros Textuais. In: Ler e Compreender os sentidos do texto. 3. ed. São Paulo: Contexto, 2009.

$\mathrm{KOCH}$, Ingedore Grunfeld Villaça. A inter-ação pela linguagem. 11. ed. São Paulo: Contexto, 2012. 134p.

MACHADO, A. R.; ABREU-TARDELLI, L. S.; LOUSADA, E. Trabalhos de pesquisa: diários de leitura para a revisão bibliográfica. São Paulo: Parábola. Editorial, 2007.

MARCUSCHI, Luiz Antônio. Da fala para a escrita: atividade de retextualização. 2. ed. São Paulo: Cortez, 2001.

MARCUSCHI, Luiz Antônio. Gêneros textuais: definição e funcionalidade. In: DIONÍSIO, Ângela Paiva; MACHADO, Anna Rachel; BEZERRA, Maria Auxiliadora (Orgs.). Gêneros Textuais e Ensino. RJ: Lucerna, 2002.

Marcuschi, Luiz Antonio. Produção textual, análise de gêneros e compreensão. São Paulo: Paráabola Editorial, 2008.

MATENCIO, Maria de Lourdes Meirelles. Estudo da língua falada e aula de língua materna: uma abordagem processual da interação professor/alunos. Campinas, SP: Mercado de Letras, 2001.

MATENCIO, Maria de Lourdes Meirelles. Atividades de (Re) textualização em práticas acadêmicas: Um estudo do resumo. Scripta, Belo Horizonte, v.6, n.11, p.109-122, $2^{\circ}$ sem. 2002.

MATENCIO, Maria de Lourdes Meirelles. Referenciação e retextualização de textos acadêmicos: um estudo do resumo e da resenha. In: CONGRESSO INTERNACIONAL DA ABRALIN, 3. Anais... Rio de Janeiro, 2003.

MATENCIO, Maria de Lourdes Meirelles; SILVA, Jane Quintiliano Guimarães. Retextualização: movimentos de aprendizagem. In: ENCONTRO INTERNACIONAL: UM ESTUDO SOBRE A CORREÇÃO DE TEXTOS: DIÁRIO DE LEITURA. Anais... v. 4, n.1. ano IV, dez. 2011.

MILLER, S. O epilinguístico: uma ponte entre o linguístico e o metalinguístico. 1998. 185f. Tese (Doutorado em Educação) - Faculdade de Filosofia e Ciências, Universidade Estadual Paulista, Marília, 1998.

MOITA LOPES, L. P. Oficina de lingüística aplicada. Campinas, SP: Mercado de Letras, 1996.

MOSCOVICI, Serge. Representações sociais: investigação em psicologia social. Tradução de Pedrinho A. Guareschi. Petrópolis, RJ: Vozes, 2003.

ROJO, R. H. R. A prática de linguagem em sala de aula: praticando os PCNs. Campinas: EDUC/Mercado de Letras, 2000. 
RUIZ, Eliana Maria Severino Donaio. Como se corrige redação na escola. - Campinas, SP: Mercado de Letras, 2001.

SCHNEUWLY, B. E DOLZ, J. (Org.). Gêneros orais e escritos na escola. Campinas: mercado de Letras, 2004.

SOARES, M. Aprender a escrever, ensinar a escrever. In: ZACCUR, E. A magia da linguagem. Rio de Janeiro: DP\&A, 1999.

VERA, A. A. Metodologia da pesquisa científica. 5. ed. Tradução de Maria Helena GuedesCrespo e Beatriz Marques Magalhães. Porto Alegre: Globo, 1979.

MEC/SEF- Secretaria de Educação Fundamental. Parâmetros Curriculares Nacionais: terceiro e quarto ciclos de ensino fundamental: língua portuguesa.Brasília, 1997, volumes 1 e 2.

\section{Como citar este artigo (Formato ABNT):}

BACK, Giselle Pupim Jorge; TEIXEIRA, Maria Ilmalucia Teixeira. A Educação no Campo e as Práticas Metodológicas. Id on Line Rev.Mult. Psic., Fevereiro/2020, vol.14, n.49, p. 559-576. ISSN: 1981-1179.

Recebido: 17/08/2019;

Aceito: 20/02/2020. 